\title{
Fluorescent Blue Materials for Efficient Organic Light-Emitting Diode with High Color Purity
}

\author{
Kyungsun Choi, Chanhyo Lee, Kwan Hee Lee, ${ }^{\dagger}$ Su Jin Park, ${ }^{\dagger}$ Seung Uk Son, Young Keun Chung, and Jong-In Hong \\ Departmentl of Chemistry, College of Natural Sciences, Seoul National University, Seonl 151-747, Korea \\ "E-mail: jihong@smiac.kr \\ "Corporate R\&D Center, Samsung SDI, Yongin 449-902, Korea \\ Received June 7, 2006
}

\begin{abstract}
We report a new series of blue dopants composed of both electron donating and electron accepting moieties in one molecule, based on nalidixic acid. The EL device derived from the dopant exhibits pure blue light emission $(0.15,0.14)$ The current efficiency is estimated to be $3.88 \mathrm{~cd} / \Lambda$ at $100 \mathrm{~cd} / \mathrm{m}^{2}$, which shows remarkable enhancement, compared to that of the host itself $\left(2.5 \mathrm{~cd} / \Lambda\right.$ at $\left.100 \mathrm{~cd} / \mathrm{m}^{2}\right)$ under the same conditions. These results demonstrate that the incorporation of a proper guest into the host in a guest-host doped system improves not only the purity of the fluorescent blue emission but also elevates its quantum efficiency, thus improving the OLED performance.
\end{abstract}

Key Words : Organic light-emitting diode, Electroluminescence, Fluorescent blue materials, Dopants

\section{Introduction}

Since the first demonstration of a green organic lightemitting diode (OLED) by Tang and VanSlyke, ${ }^{1}$ numerous organic molecules and polymers that exhibit electroluminescence (EL) in the blue, green and red spectral regions have been reported. ${ }^{2}$ The discovery of the guest-host doped emitting system is considered one of the most important developments in the OLED technology. ${ }^{3}$ This is because a proper combination of host and guest dopant results in EL combining desirable color and high efficiency. ${ }^{+}$In addition, the guesthost doped system enables the transfer of the generated exciton to the highly emissive and stable dopant site, thus minimizing the possibility of its non-radiative decay, which eventually enhances its operational stability. ${ }^{5}$ Blue dopants are essential for the development of the guest-host doped blue emitting system in a full-color display. However, there are a few efficient blue emitters compared to green- and redemitting materials due to the large energy band gap of the emitting material. Although there are several reports on guest-host doped blue emitting devices, only a limited number of blue emitting systems has practical applicability in terms of brightnes and stability. ${ }^{4,67}$ Therefore, there is still a great need for the development of new blue emitters (dopants) that give good color purity, stability and high efficiency., ${ }^{4,8}$

Herein, we report a series of blue dopants composed of both electron donating and electron accepting moieties in one molecule. These "electron push-pull" type molecules as blue dopants are noteworthy, because such "electron pushpull" structures induce a charge transfer mechanism. Thus, these structures can be tuned to result in pure blue emissions and high fluorescent quantum yields.

\section{Experimental Section}

Materials. Commercially available reagents were used without further purification unless otherwise stated. THF was distilled from sodium and benzophenone prior to use. All reactions were monitored by TLC with Kieselgel $60 \mathrm{~F}$ 254 plates from Merck Column chromatography was carried out using Merck silica gel 60 (70-230 mesh).

Methods. ' $\mathrm{H} N M R$ and ${ }^{13} \mathrm{C} \mathrm{NMR}$ in $\mathrm{CDCl}_{3}$ were recorded using a Bruker $(300 \mathrm{MHz})$ and UV-visible spectra were recorded on a BECKMAN DU650 spectrophotometer. Mass spectra were obtained using a QUATTRO LC Triple Quadrupole Tandem Mass Spectrometer and are reported in units of mass to charge $(\mathrm{m} / \mathrm{z})$. Fluorescent spectra were recorded on a Jasco FP-750 spectrophotometer. Thermal gravimetric analysis (TGA) experiment was carried out on a TA instruments TGA 2910 system. Quantum yields measurements were performed by the literature procedures using Coumarin 307 ( $\lambda_{\max }=394 \mathrm{~nm}$ and $\Phi=0.724$ ) as standards; degassed chloroform was used as a solvent.

Device fabrication. An OLED was grown on a glass substrate precoated with a $100 \mathrm{~nm}$ thick layer of indium-tin oxide (ITO) having a sheet resistance of $20 \Omega / \mathrm{m}^{2}$. Substrates were degreased with solvents and then cleaned by exposure to oxygen plasma and UV-ozone ambient. All organic and cathode metal layers were grown in succession without breaking the vacuum $\left(\sim 2 \times 10^{-8}\right.$ torr $)$ by using an in vacuo mask exchange system. After deposition, the devices were encapsulated in ambient nitrogen immediately, using a glass cover-slip sealed to the substrate with a UV-curable epoxy.

Synthesis

1-Ethyl-7-methyl-2,3-dihydro-1H-[1,8]naphthyridin-4one (1). To $21.5 \mathrm{mmol}$ of nalidixic acid in $10 \mathrm{~mL}$ of distilled tetrahydrofuran was added $26.13 \mathrm{mmol}$ of borane dimethyl sulfide complex at $0^{\circ} \mathrm{C}$ in ice bath. The solution was refluxed under nitrogen for $10 \mathrm{~h}$ at $70^{\circ} \mathrm{C}$. The reaction was quenched using $5 \mathrm{~mL}$ of methanol and $10 \mathrm{~mL}$ of $\mathrm{H}_{2} \mathrm{O}$. The solvent was evaporated and the residue was dissolved in methylene chloride. The organic phase was washed with 
saturated $\mathrm{Na}_{2} \mathrm{CO}_{3}$ solution and dried over $\mathrm{Na}_{2} \mathrm{SO}_{4}$. The solvent was evaporated to give the crude product, which was applied to column chromatography on silica gel, eluting with ethyl acetate and hexane, giving 1 ( $45 \%$ yield).

${ }^{1} \mathrm{H}$ NMR $\left(300 \mathrm{MHz}, \mathrm{CDCl}_{3}\right): \delta$ (ppm) $1.07(\mathrm{t}, J=7.1 \mathrm{~Hz}$, $3 \mathrm{H}), 2.30(\mathrm{~s}, 3 \mathrm{H}), 2.55(\mathrm{t}, J=7.3 \mathrm{~Hz}, 2 \mathrm{H}), 3.42(\mathrm{t}, J=7.3$ $\mathrm{Hz}, 2 \mathrm{H}), 3.66(\mathrm{q}, J=7.0 \mathrm{~Hz}, 2 \mathrm{H}), 6.36(\mathrm{~d}, J=7.8 \mathrm{~Hz}, 1 \mathrm{H})$, 7.82 (d, $J=7.7 \mathrm{~Hz}, 1 \mathrm{H}) ;{ }^{13} \mathrm{C}$ NMR $\left(75 \mathrm{MHz}, \mathrm{CDCl}_{3}\right): \delta$ (ppm) 12.35, 25.65, 37.53, 43.26, 45.77, 112.06, 112.72, $136.64,159.31,164.91,193.57$; ESI-MS: $\mathrm{m} / \mathrm{z}: 191.5$ $\left[\mathrm{M}+\mathrm{H}^{+}\right]$.

Blue dopants $2 \mathrm{a}-2 \mathrm{~d} .5 .26 \mathrm{mmol}$ of 1 was dissolved in 10 $\mathrm{mL}$ of distilled tetrahydrofuran at $30 \mathrm{~min}$ and followed by addition of $6.24 \mathrm{mmol}$ of lithium diisopropylamide (LDA) under nitrogen at $-78{ }^{\circ} \mathrm{C}$. The reaction mixture was stirred for $1 \mathrm{~h}$ at the same temperature. This solution was transferred to $0.97 \mathrm{mmol}$ of benzyl bromide derivatives $(\mathrm{RBr})$ in $10 \mathrm{~mL}$ of tetrahydrofuran under nitrogen at $-78^{\circ} \mathrm{C}$ and then slowly warmed to room temperature. The solution was stirred for additional $8 \mathrm{~h}$ at room temperature. This solution was quenched using $5 \mathrm{~mL}$ of saturated aqueous ammonium chloride solution. The solvent was evaporated and the residue was dissolved in methylene chloride. The organic phase was washed with saturated $\mathrm{Na}_{2} \mathrm{CO}_{3}$. All the volatiles were evaporated and dried over $\mathrm{Na}_{2} \mathrm{SO}_{4}$. The solvent was evaporated to give the crude product, which was applied to column chromatography on silica gel, eluting with ethy] acetate and hexane, giving $2 \mathbf{a - 2 d}$ (91-96\% yield).

2a: 'H NMR (300 MHz, CDCl $): \delta(\mathrm{ppm}) 1.15$ (t, $J=7.0$ $\mathrm{Hz}, 3 \mathrm{H}), 2.48(\mathrm{~s}, 3 \mathrm{H}), 2.70(\mathrm{~d}, J=13.4 \mathrm{~Hz}, 2 \mathrm{H}), 3.15(\mathrm{~s}, 2 \mathrm{H})$, $3.35(\mathrm{~d}, J=13.4 \mathrm{~Hz}, 2 \mathrm{H}), 3.86(\mathrm{q}, J=7.0 \mathrm{~Hz}, 2 \mathrm{H}), 6.57$ (d, $J$ $=7.8 \mathrm{~Hz}, 1 \mathrm{H}), 7.20-7.34(\mathrm{~m}, 10 \mathrm{H}), 8.15(\mathrm{~d}, J=7.9 \mathrm{~Hz}, 1 \mathrm{H})$; ${ }^{13} \mathrm{C} \mathrm{NMR}\left(75 \mathrm{MHz}, \mathrm{CDCl}_{3}\right): \delta$ (ppm) $12.05,25.78,39.73$, $43.95,50.70,52.12,111.76,113.30,127.09,128.56,131.25$, $138.05,158.50,164.94,196.15$; ESI-MS: $m / z \quad 371.6$ $\left[\mathrm{M}+\mathrm{H}^{+}\right]$.

2b: 'H NMR (300 MHz, $\left.\mathrm{CDCl}_{3}\right): \delta(\mathrm{ppm}) 1.14(\mathrm{t}, J=7.0$ $\mathrm{Hz}, 3 \mathrm{H}), 1.32$ (s, 18H), 2.44 (s, 3H), 2.62 (d, $J=13.4 \mathrm{~Hz}$, $2 \mathrm{H}), 3.14(\mathrm{~s}, 2 \mathrm{H}), 3.25(\mathrm{~d}, J=13.5 \mathrm{~Hz}, 2 \mathrm{H}), 3.84(\mathrm{q}, J=6.8$ $\mathrm{Hz}, 2 \mathrm{H}), 6.53$ (d, $J=7.8 \mathrm{~Hz}, 1 \mathrm{H}), 7.11(\mathrm{~d}, J=8.2 \mathrm{~Hz}, 4 \mathrm{H})$, 7.28 (d, $J=8.1 \mathrm{~Hz}, 4 \mathrm{H}), 8.09$ (d, $J=7.8 \mathrm{~Hz}, 1 \mathrm{H}){ }^{13} \mathrm{C} \mathrm{NMR}$ (75 $\mathrm{MHz}_{2} \mathrm{CDCl}_{3}$ ): $\delta$ (ppm) 11.67, 25.18, 30.88, 31.34, $34.37,38.88,50.22,51.77,111.46,112.65,124.92,130.47$, $133.62,137.63,149.31,157.93,164.24,195.97$; ESI-MS: $\mathrm{m} / \mathrm{z} 483.8\left[\mathrm{M}+\mathrm{H}^{+}\right]$.

2c: 'H NMR (300 MHz CDCl 3$): \delta(p p m) 0.24(\mathrm{t}, J=6.8$ $\mathrm{Hz}, 3 \mathrm{H}), 0.45(\mathrm{~s}, 36 \mathrm{H}), 1.63(\mathrm{~s}, 3 \mathrm{H}), 1.63$ (d, $J=13.4,2 \mathrm{H}$ ), $2.37(\mathrm{~s}, 2 \mathrm{H}), 2.4 \mathrm{l}(\mathrm{d}, J=13.4 \mathrm{~Hz}, 2 \mathrm{H}), 2.95(\mathrm{q}, J=5.2 \mathrm{~Hz}$, $2 \mathrm{H}), 5.64(\mathrm{~d}, J=7.8 \mathrm{~Hz}, \mathrm{IH}), 6.17(\mathrm{~s}, 4 \mathrm{H}), 6.42(\mathrm{~s}, 2 \mathrm{H}), 7.18$ (d, $J=7.6 \mathrm{~Hz}, 1 \mathrm{H}) ;{ }^{13} \mathrm{C} \mathrm{NMR}\left(75 \mathrm{MHz}, \mathrm{CDCl}_{3}\right): \delta(\mathrm{ppm})$ $11.81,25.69,31.99,35.20,40.69,44.07,50.88,52.17$, $112.38,113.15,120.77,125.84,136.29,138.01,150.67$, 158.42, I64.48, 196.27; ESI-MS: m/z 596.I [M+H $\left.{ }^{+}\right]$.

2d: 'H NMR (300 MHz, $\left.\mathrm{CDCl}_{3}\right): \delta(\mathrm{ppm}) 1.14(\mathrm{t}, J=6.9$ $\mathrm{Hz}, 3 \mathrm{H}), 2.54(\mathrm{~s}, 3 \mathrm{H}), 2.54$ (d, $J=13.4 \mathrm{~Hz}, 2 \mathrm{H}), 3.13(\mathrm{~s}, 2 \mathrm{H})$, 3.21 (d, $J=13.4 \mathrm{~Hz}, 2 \mathrm{H}), 3.86(\mathrm{q}, J=7.0 \mathrm{~Hz}, 2 \mathrm{H}), 6.34$ (s, $6 \mathrm{H}), 6.54(\mathrm{~d}, J=7.8 \mathrm{~Hz}, 1 \mathrm{H}), 8.10(\mathrm{~d}, J=7.8 \mathrm{~Hz}, 1 \mathrm{H}) ;{ }^{13} \mathrm{C}$ $\mathrm{NMR}\left(75 \mathrm{MHz}, \mathrm{CDCl}_{3}\right): \delta(\mathrm{ppm}) 12.05,25.58,30.55,45.43$, $50.66,52.23,55.69,99.00,106.71,108.92,109.2 \mathrm{I}, 113.3 \mathrm{I}$, 139.31, 161.21, 196.02; ESI-MS: m/z 492.0 [M+H'].

\section{Results and Discussion}

The synthetic scheme and chemical structures of chromophore 1 and blue dopants $2 a-2 d$ are shown in Scheme 1 . The precursor, chromophore 1 , was synthesized according to a routine reduction procedure from commercially available nalidixic acid and the four blue emitting materials $\mathbf{2 a - 2 d}$ were synthesized via alkylation of the $\alpha$-position of the carbonyl group in 1 in good yields (91-96\%).

A chromophore 1, 1-ethyl-7-methyl-2,3-dihydro-1H[1,8]naphthyridin-4-one, emits blue fluorescence at $453 \mathrm{~nm}$ $(0.2 \mathrm{mM}$ in chloroform). Unfortunately, 1 exists in a liquid phase that is not suited to OLED applications. Thus structural modification was required to obtain an amorphous glassy state upon thermal evaporation. The structural modification site in 1, while maintaining the original band gap of 1, can be found using the density functional theory (DFT) calculations. According to the DFT calculation at the B3LYP/ 6-3IG* level, 1 possesses a wide energy bandgap of 4.190 $\mathrm{eV}(-5.601 \mathrm{eV}$ of HOMO level and $-1.411 \mathrm{eV}$ of LUMO level), which is suited to blue dopants. The HOMO and LUMO orbitals are shown in Figure 1. The $\alpha$-position of the carbonyl group has little electron density in either HOMO or LUMO, as shown in Figure 1. Therefore, it is expected that enolate alkylation at the $\alpha$-position of the carbonyl group will lead to an amorphous glassy state.

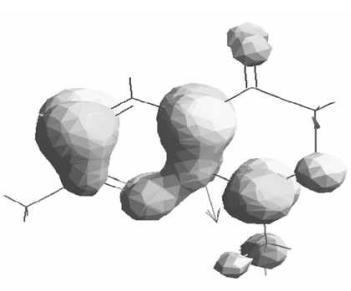

номо

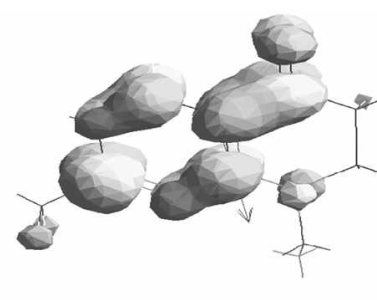

LUMO
Figure 1. Contour plots of HOMO (left) and LUMO (right) for chromophore 1 obtained by DFT calculations.

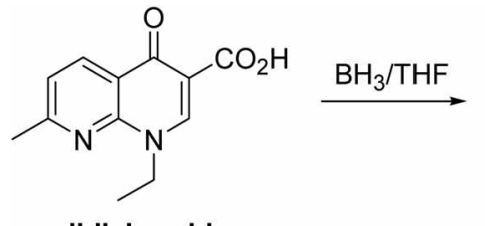

nalidixic acid

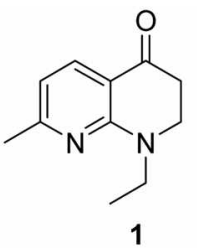

$\underset{78^{\circ} \mathrm{C}}{\stackrel{\text { 1. LDA/THF }}{\longrightarrow}}$ 2. $\mathrm{RBr}$<smiles>[R]C1([R])CN(CC)c2nc(C)ccc2C1=O</smiles>

$2 \mathrm{a}(\mathrm{R}=$ benzyl)

2b $(R=4-($ tert-butyl)benzyl)

2c $(R=3,5$-(di-tert-butyl)benzyl)

2d $(R=3,5$-(dimethoxy)benzyl)

Scheme 1. Synthesis of the blue dopants 2a-2d. 
Table 1. Isolated yıelds and physical propertıes of blue dopants 2a2d

\begin{tabular}{cccccc}
\hline Comp & $\begin{array}{c}\text { Yield } \\
(\%)\end{array}$ & $\begin{array}{c}\text { UV } \lambda_{\text {mix }} \\
(\mathrm{nm})\end{array}$ & $\begin{array}{c}\text { PL } \lambda_{\max } \\
(\mathrm{nm})\end{array}$ & $\begin{array}{c}\mathrm{Q}_{\text {solution }} \\
(\%)\end{array}$ & $\begin{array}{c}\text { TGA } \\
\left({ }^{\circ} \mathrm{C}\right)\end{array}$ \\
\hline $\mathbf{2 a}$ & 91 & 372 & 455 & 83 & 153 \\
$\mathbf{2 b}$ & 96 & 383 & 454 & 75 & 182 \\
$\mathbf{2 c}$ & 93 & 382 & 453 & 88 & 245 \\
$\mathbf{2 d}$ & 96 & 381 & 454 & 81 & 209 \\
\hline
\end{tabular}

The UV-visible absorption spectra of $\mathbf{2 a - 2 d}$ in chloroform show absorption maxima centered at $372 \mathrm{~nm}, 383 \mathrm{~nm}, 382$ $\mathrm{nm}$ and $381 \mathrm{~nm}$, respectively (Table 1 ). The solution fluorescent emission spectra of $\mathbf{2 a - 2 d}$ ( $2 \mu \mathrm{M}$ in chloroform) show similar maximum wavelengths in chloroform, at $455 \mathrm{~nm}$, $454 \mathrm{~nm}, 453 \mathrm{~nm}$ and $454 \mathrm{~nm}$, respectively (Table 1). The quantum yields of $\mathbf{2 a - 2 d}$ in chloroform were measured as ranging from 75 to $88 \%$ according to the procedure given in the literature, ${ }^{9}$ by using the well-known laser dye Coumarin 307 ( $\lambda_{\max }=394 \mathrm{~nm}$ and $\Phi=0.724$ ) as standards. By constrast, the quantum yield of chromophore 1 in chloroform is $50 \%$. The introduction of benzyl derivatives at the $\alpha$ position of the carbonyl improves the quantum efficiency significantly.

By TGA analysis, 2a-2d were found to be thermally stable, with temperatures corresponding to a $5 \%$ weight loss upon heating $\left(10^{\circ} \mathrm{C} / \mathrm{min}\right)$ under nitrogen ranging from 153 ${ }^{\circ} \mathrm{C}$ to $245^{\circ} \mathrm{C}$. $2 \mathrm{c}$ and $2 \mathrm{~d}$ had a higher decomposition temperature and were more thermally stable than $2 a$ and $2 b$

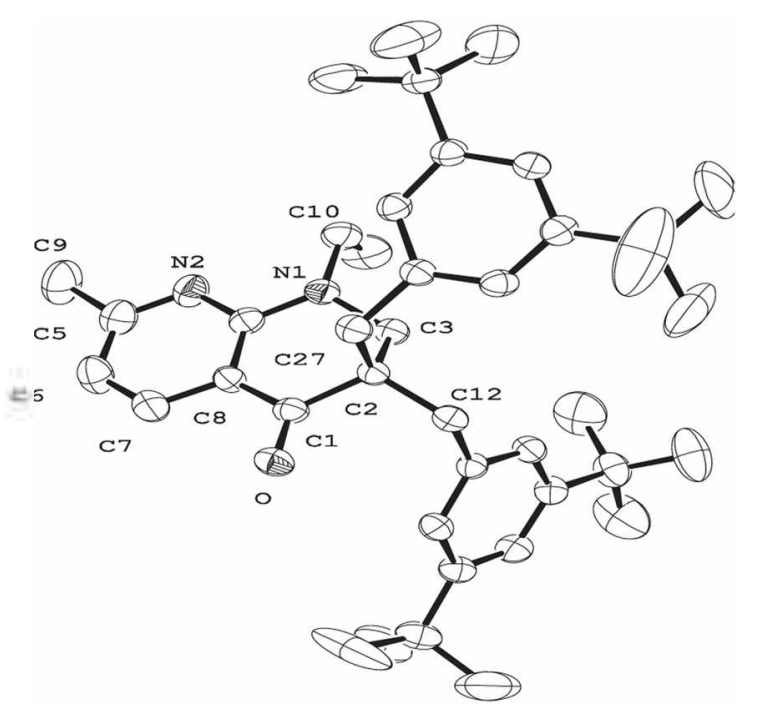

Figure 2. Molecular vew of X-ray structure of $2 \mathrm{e}$ (ORTEP drawing, thermal ellipsoid $30 \%, \mathrm{H}$ atoms are omitted for clarity)

due to their bulky substituted side chains and higher molecular weights. Differential scanning calorimetry (DSC) analysis of $\mathbf{2 a - 2 d}$ only showed their own melting temperature $\left(\mathrm{T}_{\mathrm{n}}\right)$ rather than a glass transition temperature $\left(\mathrm{T}_{2}\right)$ due to their low molecular weight.

Single crystals of $2 \mathfrak{c}$ suitable for $\mathrm{X}$-ray analysis were obtained from a mixture of methylene chloride and methanol solution left in the refrigerator. Inspection of the molecular

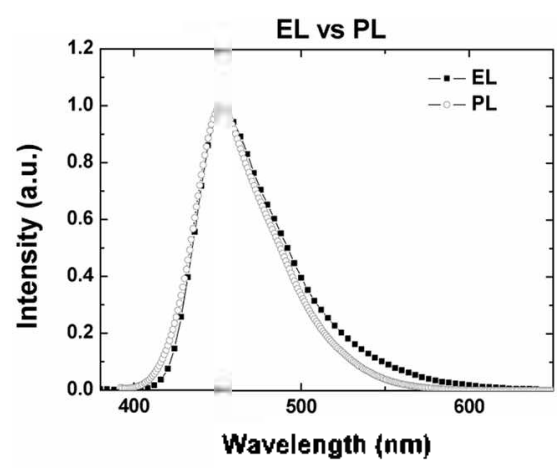

(a) EL vs PL

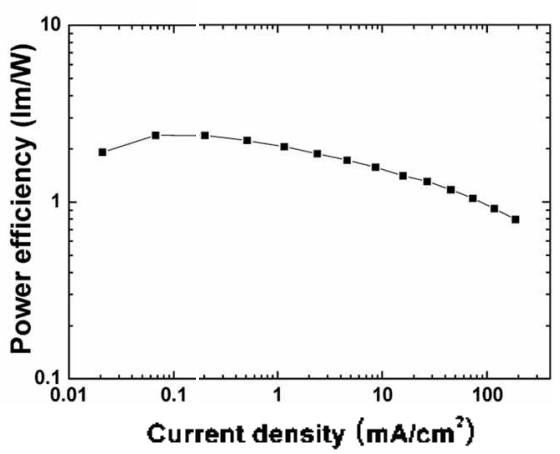

(c) Power efficiency

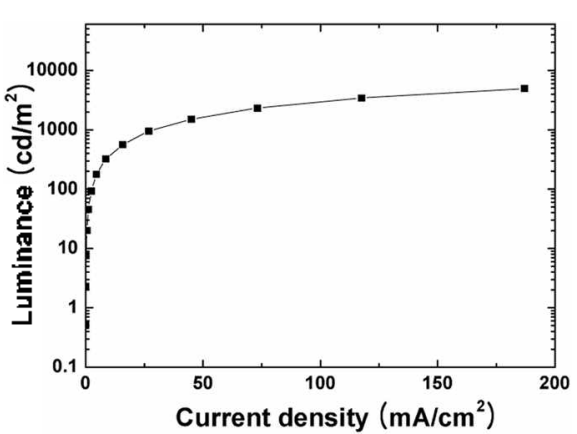

(b) Luminance

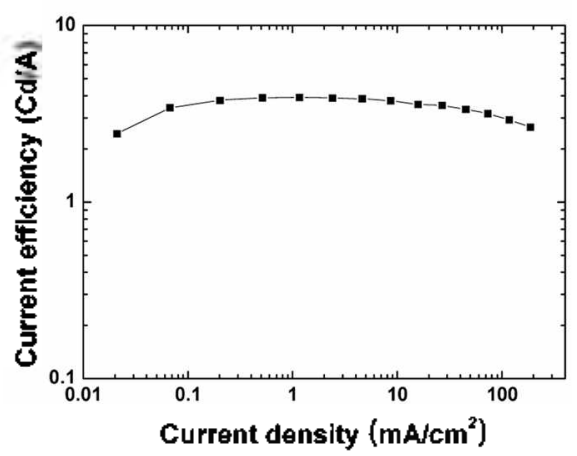

(d) Current effeiency

Figure 3. (a) EL vs PL spectrum (b) Luminance vs current density (C) Power efficiency vs current density (d) Current effeiency vs current

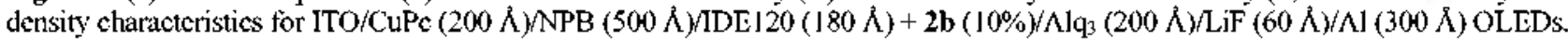


structure (Figure 2) indicates that chromophore $\mathbf{1}$ is nearly flat while the two aryl substituents are away from the chromophore plane. The bond angle of $\mathrm{C}(12)-\mathrm{C}(2)-\mathrm{C}(27)$ is $110.5^{\circ} \cdot 10$

2b has been subjected to electroluminescent (EL) studies representatively. First, a $200 \AA$ thick copper phthalocyanine $(\mathrm{CuPc})$ hole injection layer and a $500 \AA$ thick N,N-bis-(1naphthyl)-N,N'-diphenyl-1,1'-biphenyl-4,4'-diamine (NPB) hole transport layer were deposited. Next, $180 \AA$ thick IDE120, which was obtained from Idemitsu as the host and $10 \%$ of $2 \mathrm{~b}$ was blended as the guest in order to obtain energy transfer between the host and the guest. Finally, a $200 \AA$ thick electron transport layer consisting of an aluminum(III) complex of 8-hydroxyquinoline $\left(\mathrm{Alq}_{3}\right)$ was deposited and used to block holes and confine excitons to the emissive zone. Cathodes consisting of a $60 \AA$ thick layer of LiF followed by a $3000 \AA$ thick layer of $\mathrm{Al}$ were pattemed using a shadow mask with an array of $2 \mathrm{~mm} \times 2 \mathrm{~mm}$ openings. According to the procedures described above, an OLED device with the configuration of ITO/CuPc $(200 \AA) / \mathrm{NPB}$ $(500 \AA) / \mathrm{LDE} 120(180 \AA)+\mathbf{2 b}(10 \%) / \mathrm{Alq}_{3}(200 \AA) / \mathrm{LiF}(60$ $\AA) / \mathrm{Al}(300 \AA)$ was fabricated.

Figure 2 shows EL versus PL spectrum, luminance versus current density, power efficiency versus current density, and current effciency versus current density characteristics for the device using $\mathbf{2 b}$. This device exhibits pure blue light emission, with a maximum centered at $456 \mathrm{~nm}$, which is similar to the PL spectrum of $\mathbf{2 b}$, indicating that the emission originates purely from chromophore 1 . The emission falls in the blue region at a turn-on voltage of $4.0 \mathrm{~V}$. The CIE color coordinate is $\mathrm{x}=0.15$ and $\mathrm{y}=0.14$ at $6.54 \mathrm{~V}$. This value well suits its purpose as a blue emitting material for OLED. It is noteworthy that the CIE color coordinate $(0.15$, 0.14 ) in the guest-host doped system with $2 \mathrm{~b}$ as a guest is obviously close to the color coordinate of the host $(0.15$, 0.13 ) without guest doping. A peak current efficiency of $3.92 \mathrm{~cd} / \mathrm{A}$ at $1.2 \mathrm{~mA} / \mathrm{cm}^{2}$ and power efficiency of $2.42 \mathrm{~lm} / \mathrm{W}$ at $0.07 \mathrm{~mA} / \mathrm{cm}^{2}$ are obtained. More importantly, the current efficiency is estimated to be $3.88 \mathrm{~cd} / \mathrm{A}$ at $100 \mathrm{~cd} / \mathrm{m}^{2}$, which shows remarkable enhancement, compared to that of the host itself $\left(2.5 \mathrm{~cd} / \mathrm{A}\right.$ at $\left.100 \mathrm{~cd} / \mathrm{m}^{2}\right)$ under the same conditions.

In summary, we have synthesized new fluorescent blue dopants consisting of both electron donating and electron accepting moieties in a single molecule. They exhibit high fluorescent quantum yields due to an intramolecular charge transfer mechanism. The photoluminescent properties of the synthesized molecules were found to be suitable for blue dopants. These results demonstrate that the incorporation of a proper guest into the host in a guest-host doped system improves not only the purity of the fluorescent blue emission but also elevates its quantum efficiency, thus improving the OLED performance.

Acknowledgements. This work was supported by the CMDS (KOSEF), Seoul R\&BD, and SSDIP.

Supporting Information Available: Crystallographic data are available on request from the correspondence author.

\section{References}

I. Tang, C. W, VanSlyke, S. A. Appl. Phys, Lett. 1987, 51, 913.

2. Takeo, W. Organic Electroluminescent Material and Devices; CRC PRESS: 1997 ; Vol. $289, \mathrm{p} 16$.

3. Tang, C. W.; VanSlyke, S. A.; Chen, C. H. J. Appl. Phys. 1989, 65 , 3610 .

4. Lee, M. T.; Liao, C. H.; Tsai, C. H.; Chen, C. H. Ach. Mater. 2005, I7, 2493.

5. VanSlyke, S. A.; Bryan, P. S.; Tang, C. W. The 8 th International Workshop on EL'96, Inorganic \& Organic EL '96, Berlin', Manch, R. H.; Gumlich, H. E. Eds.; 1996; pp 195-199.

6. (a) Wu, Y. Z.; Sun, R. G.; Zheng, X. Y.; Zhu, W. Q.; Jiang, X. Y.; Zhang, Z. L.; Xu, S. H. J. Soc. Int. Disp. 2004, 12, 501. (b) Lee, J.$\mathrm{H}_{\text {.; }}$ Lin, T.-C.; Liao, C.-C. Proceedings of SPIE 2005, $1,8,5740$.

7. (a) Gao, Z.; Lee, C. S.; Bello, I.; Lee, S. T.; Chen, R.M.; Luh, T.Y.; Shi, J.; Tang, C. W. Appl. Phys. Lett. 1999, 74, 865. (b) Mi, B. X.; Gao, Z. Q.; Lee, C. S.; Lee, S. T.; Kwong. H. L.; Wong. N. B. Appl. Phys. Lett. 1999, 75, 4055. (c) Noda, T.; Shirota, Y. $J$. Lumin. 2000, 87, I168. (d) Kim, Y. H.; Shin, D. C.; Kim, S.-H.; Ko, C.-H.; Yu, H.-S.; Chae, Y.-S.; Kwon, S. K. Adt. Mater. 2001, 13, 1690. (e) Leung, L. M.; Lo, W. Y.; So, S. K.; Lee, K. M.; Choi, W. K. J. Am. Chem. Soc. 2000, 122, 5640. (I) Tao, X. T.; Suzuki, H.; Wada, T.; Miyata, S.; Sasabe, H.J. An. Chem. Soc. 1999, 121, 9447. (g) Wong, K.-T.; Chien, Y.-Y.; Chen, R.-T.; Wang, C.-F.; Lin, Y.-T.; Chiang, H.-H.; Hsieh, P.-Y.; Wu, C.-C.; Chou, C. H.; Su, Y, O.; Lee, G.-H.; Peng, S.-M. J. Am. Chem. Soc. 2002, 124, 11576. (h) Chan, L.-H.; Lee, R.-H.; Hsieh, C.-F.; Yeh, H.-C.; Chen, C.-T. J. Am. Chem, Soc, 2002, 124,6469 . (1) Tao, Y, T.; Balasubramaniam, E.; Danel, A.; Wilsa, A.; Tomasik, P. J. Mot. Chem. 2001, 11,768 .

8. (a) Lee, M.-T.; Chen, H.-H.; Liao, C.-H.; Tsai, C.-H.; Chen, C. H. Appl. Phy. Lett, 2004, 85, 3301, (b) Hosokawa, C.; Higashi, H.; Nakamura, H.; Kusumoto, T. Appl. Phy. Lett, 1995, 67, 3853. (c) Shi, J.; Tang, C. W. Appl. Phy: Lett, 2002, 80, 3201.

9. Suzanne, F. F.; Dominique, L. J. Chem. Edh. 1999, 76, 12.

10. For details, see the Supporting Information. Crystallographic data for $\mathbf{2 c}$ reported here have been deposited with CCDC (Deposition No. CCDC-609973). These data can be obtained free of charge via www.cedc.cam.ac.uk/conts/retrieving.himl (or from the Cambridge Crystallographic Data Centre, 12 Union Road, Cambridge CB2 1EZ, UK, e-mail: deposit@ccdc.cam.ac.uk). 